Research Article

\title{
The effect of the antioxidant drug "U-74389G" on lactate dehydrogenase levels during ischemia reperfusion injury in rats
}

\begin{abstract}
Background: This experimental study examined the effect of the antioxidant drug "U-74389G", on a rat model and particularly in a generalized ischemia - reperfusion protocol. The effects of that molecule were studied biochemically using blood mean lactate dehydrogenase (LDH) levels.
\end{abstract}

Methods: 40 rats of mean weight $231.875 \mathrm{~g}$ were used in the study. LDH levels were measured at $60 \mathrm{~min}$ of reperfusion (groups A and C) and at $120 \mathrm{~min}$ of reperfusion (groups $\mathrm{B}$ and D). The drug U-74389G was administered only in groups C and D.

Results: U-74389G administration kept significantly increased the predicted LDH levels by $18.78 \%+4.52 \%(\mathrm{P}=0.0001)$. Reperfusion time non-significantly decreased the predicted LDH levels by $3.75 \% \pm 5.46 \%(\mathrm{p}=0.4103)$. However, $\mathrm{U}-74389 \mathrm{G}$ administration and reperfusion time together kept significantly increased the predicted LDH levels by $10.43 \% \pm 2.82 \%(\mathrm{P}=0.0005)$.

Conclusion: U-74389G administration whether it interacted or not with reperfusion time kept significantly increased short - term the LDH levels.

Keywords: ischemia, U-74389G, lactate dehydrogenase, reperfusion
Volume 3 Issue I - 2016

Tsompos C,' Panoulis C, ${ }^{2}$ Toutouzas K, ${ }^{3}$ Triantafyllou A, ${ }^{4}$ Zografos G, ${ }^{3}$ Papalois A $^{5}$

'Department of Obstetrics \& Gynecology, Messolonghi County Hospital, Greece

${ }^{2}$ Department of Obstetrics \& Gynecology, Athens University, Greece

${ }^{3}$ Department of Surgery, Athens University, Greece ${ }^{4}$ Department of Biologic Chemistry, Athens University, Greece ${ }^{5}$ Exprerimental Research Center ELPEN Pharmaceuticals, Greece

Correspondence: Tsompos C, Department of Obstetrics \& Gynecology, Messolonghi County Hospital, Nafpaktou street, Mesologi 30200, Etoloakarnania, Greece, Tel 3.0263 I E+ I I, Fax 3.02107E+ I , Email Tsomposconstantinos@gmail.com

Received: August 10,2016 | Published: August 29, 2016

\section{Introduction}

Permanent or transient damage with serious implications on adjacent organs and systems may be due to tissue ischemia reperfusion (IR). The use of U-74389G in IR has been a challenge for many years. However, although the progress was significant, several practical questions have not clarified. They include: a) how potent U-74389G should be b) when should it be administered and c) at what optimal dose U-74389G should be administered. The promising effect of U-74389G in tissue protection has been noted in several IR studies. U-74389G or also known as 21-[4-(2,6-di-1-pyrrolidinyl4-pyrimidinyl)-1-piperazinyl]-pregna-1,4,9(11)-triene-3,20-dione maleate salt is an antioxidant which prevents both arachidonic acidinduced and iron-dependent lipid peroxidation. ${ }^{1}$ It protects against IR injury in animal organs such as heart, liver and kidney models. These membrane-associating antioxidants are particularly effective in preventing permeability changes in brain microvascular endothelial cells monolayers. ${ }^{2}$ A meta-analysis of 23 published seric variables, coming from the same experimental setting, tried to provide a numeric evaluation of the U-74389G efficacy at the same endpoints (Table 1). Several publications addressed trials of other similar antioxidant molecules to which the studied molecule U-74389G belongs to.

The aim of this experimental study was to examine the effect of the antioxidant drug "U-74389G" on rat model and particularly in a generalized ischemia - reperfusion (IR) protocol. The effects of that molecule were studied by measuring blood mean lactate dehydrogenase (LDH) levels.

\section{Materials and methods}

\section{Animal preparation}

This basic experimental research was licensed by Veterinary Address of East Attiki Prefecture under 3693/12-11- 2010 \& 14/10-1-
2012 decisions. All consumables, equipment and substances, were a grant of Experimental Research Centre of ELPEN Pharmaceuticals Co. Inc. S.A. at Pikermi, Attiki. Accepted standards of humane animal care were adopted for Albino female Wistar rats. 7 days pre-experimental normal housing included ad libitum diet in laboratory. Prenarcosis of animals proceeded of continuous intra-experimental general anesthesia, ${ }^{3-6}$ oxygen supply, electrocardiogram and acidometry. Postexperimental euthanasia did not permitted awakening and preservation of the animals. Rats were randomly delivered to four experimental groups by 10 animals in each one, using following protocols of IR: Ischemia for $45 \mathrm{~min}$ followed by reperfusion for $60 \mathrm{~min}$ (group A); ischemia for $45 \mathrm{~min}$ followed by reperfusion for $120 \mathrm{~min}$ (group B); ischemia for $45 \mathrm{~min}$ followed by immediate $\mathrm{U}-74389 \mathrm{G}$ intravenous (IV) administration and reperfusion for $60 \mathrm{~min}$ (group C); ischemia for $45 \mathrm{~min}$ followed by immediate U-74389G IV administration and reperfusion for $120 \mathrm{~min}$ (group D). The dose of U-74389G was 10 $\mathrm{mg} / \mathrm{Kg}$ body mass of animals. Ischemia was caused by laparotomic clamping inferior aorta over renal arteries with forceps for $45 \mathrm{~min}$. Reperfusion was induced by removing the clamp and re-establishing inferior aorta patency. U-74389G was administered at the time of reperfusion; through catheterized inferior vena cava. The LDH levels were determined at 60th min of reperfusion (for $\mathrm{A}$ and $\mathrm{C}$ groups) and at 120th min of reperfusion (for B and D groups). Fourty female Wistar albino rats were used (mean weight $231.875 \mathrm{~g}$ [Standard Deviation (SD): $36.59703 \mathrm{~g}$ ], with minimum weight $165 \mathrm{~g}$ and maximum weight $320 \mathrm{~g}$. Rats' weight could be potentially a confusing factor, e.g. more obese rats to have higher LDH levels. This assumption was also investigated.

\section{Control groups}

20 control rats (mean mass $252.5 \mathrm{~g}$ [SD: $39.31988 \mathrm{~g}$ ]) experienced ischemia for $45 \mathrm{~min}$ followed by reperfusion. 
Table I The U-74389G influence (+SD) on the levels of some seric variables ${ }^{3}$ concerning reperfusion (rep) time

\begin{tabular}{|c|c|c|c|c|c|c|c|c|}
\hline Variable & Ih rep & p-value & I.5h rep & p-value & 2h rep & p-value & Interaction of U-74389G and Rep & p-value \\
\hline WBCC & 0.3544 & 0.0914 & 0.4199 & 0.0045 & 0.5609 & 0.0185 & 0.2973 & 0.0004 \\
\hline RBCC & 0.021 & 0.7161 & 0.0096 & 0.8106 & -0.0005 & 0.9762 & 0.0158 & 0.4911 \\
\hline Hematocrit & 0.0858 & 0.0852 & 0.0698 & 0.0435 & 3.9244 & 0.2608 & 0.0449 & 0.0196 \\
\hline Hemoglobin & 0.08 & 0.0925 & 0.06 & 0.0604 & 0.059 & 0.3544 & 0.038 & 0.0423 \\
\hline $\mathrm{MCH}$ & 0.0273 & 0.0663 & 0.0297 & 0.0001 & 0.0374 & 0.0003 & $1.33 \%+0.36 \%$ & 0.0005 \\
\hline $\mathrm{MCHC} 4$ & 0.0024 & 0.482 & -0.0032 & 0.1124 & -0.0028 & 0.1603 & -0.0032 & 0.0655 \\
\hline RbcDW & -0.024 & 0.0667 & -0.0269 & 0.0175 & -0.0073 & 0.1383 & -0.0115 & 0.679 \\
\hline Platelet count & -0.0839 & 0.0647 & -0.0704 & 0.0303 & -0.0005 & 0.2939 & -0.0254 & 0.0857 \\
\hline Platelet-crit & 0.1367 & 0.6373 & 0.1552 & 0.1064 & 0.2369 & 0.0833 & 0.1045 & 0.0712 \\
\hline PDW & 0.0198 & 0.2368 & 0.0255 & 0.0314 & 0.0382 & 0.0807 & 0.0142 & 0.0396 \\
\hline Glucose & $-0.029 \mid$ & 0.0663 & -0.065 I & 0.0001 & -0.0822 & 0.0003 & -0.0348 & 0.0005 \\
\hline Creatinine5 & -0.0725 & 0.0663 & -0.1596 & 0.0001 & -0.1997 & 0.0003 & -0.0853 & 0.0005 \\
\hline Uric acid6 & 0.353 & 0.1614 & 0.2453 & 0.096 & 0.2211 & 0.3946 & 0.1042 & 0.3873 \\
\hline Total protein & -0.0249 & 0.0663 & -0.0558 & 0 & -0.0704 & 0 & -0.0298 & 0 \\
\hline ALP & 0.3503 & 0.0663 & 0.396 & 0.0001 & 0.5081 & 0.0003 & 0.2254 & 0.0005 \\
\hline $\mathrm{ACP}$ & -0.9159 & 0.0006 & $-1.136 \mid$ & 0 & -1.2274 & 0 & -0.6482 & 0 \\
\hline CPK & 0.6807 & 0.0012 & 0.5254 & 0.026 & 0.4661 & 0.4951 & 0.2796 & 0.077 \\
\hline Sodium & 0.0188 & 0.0707 & 0.0078 & 0.7714 & 0.0016 & 0.3995 & 0.0004 & 0.3693 \\
\hline Chloride & 0.0019 & 0.4533 & -0.0044 & 0.0879 & -0.006 & 0.1113 & -0.0037 & 0.0159 \\
\hline Calcium & $0 \%+1.75 \%$ & I & 0.0096 & 0.8782 & 0.0126 & 0.8492 & 0.0078 & 0.8245 \\
\hline Phosphorus & 0.0328 & 0.7966 & 0.0171 & 0.5789 & 0.0348 & 0.8129 & 0.0091 & $0.577 \mid$ \\
\hline Magnesium & 0.0492 & 0.7033 & 0.0247 & $0.917 \mid$ & 0.0338 & 0.7161 & 0.0494 & 0.8228 \\
\hline Mean & 0.2852 & 0.2707 & 0.2885 & 0.2268 & 0.304 & 0.3011 & 0.1682 & 0.2107 \\
\hline
\end{tabular}

\section{Group A}

Reperfusion lasted for $60 \mathrm{~min}$ ( $\mathrm{n}=10$ controls rats) mean mass 243g [SD: 45.77724g], mean LDH levels 1609.9 IU/L [SD: 834.4269 IU/L] (Table 2).

Table 2 Weight and LDH mean levels and Std. Dev. of groups

\begin{tabular}{llll}
\hline Groups & Variable & Mean & Std. Dev \\
\hline A & Weight LDH & $243 \mathrm{~g} 1609.9 \mathrm{IU} / \mathrm{L}$ & $45.77724 \mathrm{~g} 834.4269 \mathrm{IU} / \mathrm{L}$ \\
B & WeightLDH & $262 \mathrm{~g} 1622.6 \mathrm{IU} / \mathrm{L}$ & $31.10913 \mathrm{~g} 793.438 \mathrm{IU} / \mathrm{L}$ \\
C & WeightLDH & $212.5 \mathrm{~g} 2568.3 \mathrm{IU} / \mathrm{L}$ & $17.8341 \mathrm{Ig} 622.0566 \mathrm{IU} / \mathrm{L}$ \\
D & WeightLDH & $210 \mathrm{~g} 2259.5 \mathrm{IU} / \mathrm{L}$ & $18.10463 \mathrm{~g} 524.131 \mathrm{I} \mathrm{IU} / \mathrm{L}$
\end{tabular}

\section{Group B}

Reperfusion lasted for $120 \mathrm{~min}(\mathrm{n}=10$ controls rats) mean mass 262 g [SD: 31.10913g], mean LDH levels 1622.6 IU/L [SD: 793.438 IU/L] (Table 2).

\section{Lazaroid (L) group}

$20 \mathrm{~L}$ rats (mean mass 211.25g [SD: 17.53755g] experienced ischemia for $45 \mathrm{~min}$ followed by reperfusion in the beginning of which $10 \mathrm{mg} \mathrm{U}-74389 \mathrm{G} / \mathrm{kg}$ body weight were IV administered.

\section{Group C}

Reperfusion lasted for $60 \mathrm{~min}(\mathrm{n}=10 \mathrm{~L}$ rats) mean mass $212.5 \mathrm{~g}$ [SD: 17.83411g], mean LDH levels 2568.3 IU/L [SD: 622.0566 IU/L] (Table 2).

\section{Group D}

Reperfusion lasted for $120 \mathrm{~min}(\mathrm{n}=10 \mathrm{~L}$ rats) mean mass $210 \mathrm{~g}$ [SD: $18.10463 \mathrm{~g}$ ], mean LDH levels 2259.5 IU/L [SD: $524.1311 \mathrm{IU} / \mathrm{L}$ ] (Table 2).

\section{Statistical analysis}

The generalized linear model (GLM) is a flexible generalization of ordinary linear regression that allows for response variables that have error distribution models other than a normal distribution. The GLM generalizes linear regression by allowing the linear model to be related to the response variable via a link function and by allowing the magnitude of the variance of each measurement to be a function of its predicted value. It is proposed an iteratively reweighted least squares method for maximum likelihood estimation of the model parameters as remaining the most popular. Ordinary linear regression predicts the expected value of a given unknown quantity (the response variable, a random variable) as a linear combination of a set of observed values (predictors). This implies that a constant change in a predictor leads to a constant change in the response variable (i.e. a linear-response model). This is appropriate when the response variable has a normal distribution (intuitively, when a response variable can vary essentially indefinitely in either direction with no fixed "zero value", or more generally for any quantity that only varies by a relatively small amount, e.g. the rats weights). The investigation of a high LDH value may outcome to one of the 3 following explanations: it may be proportional to tissue damage size, or may be influenced by the U-74389G, or may be proportional to weight of the post-injury animal or tissue. Only the GLM testing associating the LDH levels with the weights can provide an answer to this question. If the response is statistically significant, then the variation of LDH levels is also due to the animals' weight. This variable must be eliminated and find other LDH levels which will reflect only the degree of the effect of the drug as the tissue damage size is the same for all animals. These new LDH levels are the predicted LDH levels. However, these assumptions are inappropriate for some types of response variables. For example, in cases where the response variable is expected to be always positive and varying over a narrow or wide range, constant input changes lead to geometrically varying, rather than constantly varying, output 
changes (e.g. the study times: 1 hour or 2 hours). Similarly, a model that predicts a probability of making a yes/no choice (a Bernoulli variable) is even less suitable as a linear-response model, since probabilities are bounded on both ends (they must be between 0 and 1, e.g. the drug or no administration). GLM cover all these situations by allowing for response variables that have arbitrary distributions (rather than simply normal distributions) and for an arbitrary function of the response variable (the link function) to vary linearly with the predicted values (rather than assuming that the response itself must vary linearly). Every weight and LDH level group was compared with each other by statistical standard t-tests (Table 3). Any significant difference among LDH levels, was investigated whether owed in any potent significant weight one. The application of GLM with dependant variable the LDH levels was followed. The 3 independent variables were the U-74389G or no drug administration, the reperfusion time and both variables in combination. Inserting the rats' weight also as an independent variable at GLM analysis, a very significant relation resulted in ( $\mathrm{p}=0.0070)$, so as to further investigation was needed. The predicted LDH values, adjusted for rats' weight were calculated and are depicted at Table 4 . Afterwards, every predicted LDH level group was compared with each other by statistical standard t-tests (Table 5). The application of GLM with dependant variable the predicted LDH levels was followed. The 3 independent variables were again the same as previously.

Table 3 Statistical significance of mean values difference for groups (DG) after statistical standard $t$ test application

\begin{tabular}{llll}
\hline DG & Variable & Difference & p-value \\
\hline A-B & Weight LDH & $-19 \mathrm{~g}$ & 0.24230 .9738 \\
& & $-12.7 \mathrm{IU} / \mathrm{L}$ & \\
A-C & Weight LDH & $30.5 \mathrm{~g}-958.4 \mathrm{IU} / \mathrm{L}$ & 0.06740 .0369 \\
A-D & Weight LDH & $33 \mathrm{~g}-649.6 \mathrm{IU} / \mathrm{L}$ & 0.05740 .0694 \\
B-C & Weight LDH & $49.5 \mathrm{~g}-945.7 \mathrm{IU} / \mathrm{L}$ & 0.00190 .0167 \\
B-D & Weight LDH & $52 \mathrm{~g}-636.9 \mathrm{IU} / \mathrm{L}$ & 0.00040 .0101 \\
C-D & Weight LDH & $2.5 \mathrm{~g}-308.8 \mathrm{IU} / \mathrm{L}$ & 0.70430 .3258 \\
\hline
\end{tabular}

Table 4 Mean predicted LDH values adjusted for weight and Std. Dev. of groups

\begin{tabular}{lll} 
Groups & Mean & Std. Dev \\
\hline A & $1913.476 \mathrm{IU} / \mathrm{L}$ & $418.0609 \mathrm{IU} / \mathrm{L}$ \\
B & $1739.958 \mathrm{IU} / \mathrm{L}$ & $284.1044 \mathrm{IU} / \mathrm{L}$ \\
C & $2192.017 \mathrm{IU} / \mathrm{L}$ & $162.8703 \mathrm{IU} / \mathrm{L}$ \\
$D$ & $2214.848 \mathrm{IU} / \mathrm{L}$ & $165.3407 \mathrm{IU} / \mathrm{L}$ \\
\hline
\end{tabular}

Table 5 Statistical significance of mean predicted values difference for groups (DG) after statistical standard t test application

\begin{tabular}{lll}
\hline DG & Difference & p-value \\
\hline A-B & I73.5I77 IU/L & 0.2423 \\
A-C & $-278.5414 \mathrm{IU} / \mathrm{L}$ & 0.0674 \\
A-D & $-301.3726 \mathrm{IU} / \mathrm{L}$ & 0.0574 \\
B-C & $-452.059 \mathrm{IIU} / \mathrm{L}$ & 0.0019 \\
B-D & $-474.8903 \mathrm{IU} / \mathrm{L}$ & 0.0004 \\
C-D & $-22.831 \mathrm{I} \mathrm{IU} / \mathrm{L}$ & 0.7043 \\
\hline
\end{tabular}

\section{Results}

The first GLM resulted in: U-74389G administration kept significantly increased the LDH levels by $797.65 \mathrm{IU} / \mathrm{L}[352.6114$ $\mathrm{IU} / \mathrm{L}-1242.689 \mathrm{IU} / \mathrm{L}](\mathrm{P}=0.0008)$. This finding was in accordance with the results of standard t-test $(\mathrm{p}=0.0016)$. Reperfusion time nonsignificantly decreased the LDH levels by $148.05 \mathrm{IU} / \mathrm{L}[-662.1633$ $\mathrm{IU} / \mathrm{L}-366.0633 \mathrm{IU} / \mathrm{L}](\mathrm{P}=0.5634)$, also in accordance with standard t-test $(\mathrm{p}=0.5383)$. However, $\mathrm{U}-74389 \mathrm{G}$ administration and reperfusion time together kept significantly increased the LDH levels by 378.9364 $\mathrm{IU} / \mathrm{L}$ [93.47671 IU/L - 664.396 IU/L] $(\mathrm{P}=0.0106)$. Reviewing the above and Table 3, the table 6 sums up concerning the alteration influence of U-74389G in connection with reperfusion time. The second GLM resulted in: U-74389G administration kept significantly increased the predicted LDH levels by 376.7159 IU/L [198.7321 $\mathrm{IU} / \mathrm{L}$ - 554.6996 IU/L] $(\mathrm{P}=0.0001)$. This finding was in accordance with the results of standard t-test $(\mathrm{p}=0.0002)$. Reperfusion time nonsignificantly decreased the predicted LDH levels by $75.34327 \mathrm{IU} / \mathrm{L}$ [-290.6826 IU/L - 139.9961 IU/L] $(\mathrm{P}=0.4831)$, also in accordance with standard t-test $(\mathrm{p}=0.3375)$. However, $\mathrm{U}-74389 \mathrm{G}$ administration and reperfusion time together kept significantly increased the LDH levels by $209.6325 \mathrm{IU} / \mathrm{L}[98.52261 \mathrm{IU} / \mathrm{L}-320.7424 \mathrm{IU} / \mathrm{L}](\mathrm{P}=$ 0.0005 ). Reviewing the above and Table $5,7 \& 8$ sums up concerning the alteration influence of $\mathrm{U}-74389 \mathrm{G}$ in connection with reperfusion time.

\section{Discussion}

LDH is found extensively in body tissues, such as blood cells, heart muscle and liver. Because it is released during tissue damage, it is a marker of common injuries like muscular failure and fatigue, tissue breakdown or turnover and hemolysis. It concerns all the ischemic tissues under the clapping level in the present experiment. A lot of clinical observations show how LDH levels are influenced in ischemic cases. Pisarenko et al. ${ }^{7}$ combined enhanced functional recovery with an increase in $\mathrm{LDH}$ and $\mathrm{LDH} /$ pyruvate ratio levels leakage in early perfusate of isolated working rat IR hearts. Wang et al. ${ }^{8}$ found remarkable decreases in both LDH levels release and myocardial infarction size in mouse transgenic IR hearts over expressing functional consequence of microRNAs miR-494, than wild-type ones. Yamagishi et al. ${ }^{9}$ found the levels of LDH released into the IR coronary effluent inversely lower in $70 \%$ reduced fed Wistar rats than in ad-libitum fed rats. These results suggested that severe, short-term food restriction improves ischemic tolerance in rat hearts. $\mathrm{Xu}$ et al first determined ${ }^{10}$ the cardiomyocyte shortening and then the roles of LDH release in culture medium in isolated IR myocytes of female rats. Ciminelli et al. ${ }^{11}$ found released LDH levels in the IR coronary effluent similar in treadmill running trained rats than control ones. Hoeven et al. ${ }^{12}$ found progressive organ; particularly kidney dysfunction and inflammatory responses most pronounced in hemodynamically unstable brain-dead donors studied by monitoring LDH levels in Wistar rats. Wang et al evaluated ${ }^{13}$ the released LDH levels significantly less impaired in gene-targeted NHE1-null mutant (Nhe1-/-) mice IR hearts relative to wild-type ones, in absence of NHE1 inhibitor. Wang et al..$^{14}$ measured decreased release of skeletal muscle intracellular enzyme LDH in experimental groups protected by ischemic preconditioning (IP) in limb IR injury compared with the control ones. Baron et al. ${ }^{15}$ assessed no significant influence of mycophenolic acid (MPA) on postischemic efflux rates of LDH levels in rat IR liver. Ko et al. ${ }^{16}$ caused a LDH leakage to a smaller extent in isolated-perfused brief IR hearts of control and diabetic rats. Kume et al. ${ }^{17}$ attenuated the IR liver damage by IP improving the restoration of hepatic function during reperfusion as explained by LDH release. Jaeschke et al. ${ }^{18}$ assumed the intracellular generation of reactive oxygen species in IR hepatocytes injury of Fischer rats by LDH release.

Also, LDH levels may be influenced by $\mathrm{U}-74389 \mathrm{G}$ administration. Shopova VL et al. ${ }^{19}$ considered that paraquat forms reactive oxygen species and increases the lipid peroxidation in the pulmonary cells. Paraquat dichloride was administered orally at $80 \mathrm{mg} / \mathrm{kg}$ in Wistar rats. 
The lazaroid U-74389G was injected intraperitoneally twice - with $10 \mathrm{mg} / \mathrm{kg}$ and $5 \mathrm{mg} / \mathrm{kg}$ respectively. Isolated application of paraquat increased enzyme activities of LDH content in bronchoalveolar lavage fluid (BALF). The combined treatment with paraquat and U-74389G significantly elevated the enzyme activities of LDH less than the separate administration of paraquat. It is concluded that the lazaroid U-74389G reduces the pneumotoxic effects of paraquat, estimated by biochemical markers in BALF until day 3 after the treatment. Vignes et al. ${ }^{20}$ suggested a partial neuroprotective effect of free radical scavengers since lipid peroxidation is a key cellular event in neuronal injury, and its inhibition with lazaroids could help to reduce brain ischemic lesions ${ }^{20}$ by a LDH assay in rats. The excessive production of free radicals by oxidative stress is engaged in a large variety of diseases. Lazaroids (U-74389G), added to cultures, at different concentrations (10-7-5 M), caused a reduction in cortical neuronal death by $34.5 \%$. Alhan $\mathrm{E}$ et al. ${ }^{21}$ induced acute necrotizing pancreatitis in rats resulted in a significant increase in serum LDH levels in BALF. U-74389G may be used in the treatment of lung injury during acute pancreatitis. Monte et al. ${ }^{22}$ impaired significantly glutamate clearance when astrocytes were preincubated with 1-methyl-4-phenylpyridinium MPP (+). Astrocytes are the site of the toxic (MPP (+)) metabolite production. This effect became more pronounced by prolonging the incubation in the presence of MPP $(+)$. Indeed, the lazaroid antioxidant U-74389G, was not capable of restoring glutamate net uptake. These results indicate that, by acting as a mitochondrial poison, MPP (+) impairs energy metabolism of astrocytes and significantly reduces their ability to maintain low levels of extracellular glutamate. Fukuma
$\mathrm{K}$ et al. ${ }^{23}$ compared the efficacy of U-74389G in endotoxin-induced liver injury. Lipopolysaccharide (Escherichia coli, $30 \mathrm{mg} / \mathrm{kg}$ given intraperitoneally [IP]) and U-74389G (3mg/kg IP) were administered simultaneously in male IR mice. U-74389G treatment significantly increased survival rates 48 hours after lipopolysaccharide injection and decreased hepatic enzyme release. These findings suggest that U-74389G can suppress proinflammatory gene up-regulation and ameliorate endotoxin shock. Ishizaki $\mathrm{N}$ et al. ${ }^{24}$ significantly improved dogs survival 3-fold compared with the control ones after lazaroids administration IV at $5 \mathrm{mg} / \mathrm{kg}$ before IR. Elevation of liver enzymes after reperfusion was markedly attenuated in treated groups. Structural abnormalities were markedly ameliorated showing less neutrophil infiltration in post-IR liver. Warm IR liver injury was attenuated with lazaroid compounds. Campo GM et al. ${ }^{25}$ reduced the increased plasma LDH levels by $33.03 \%$ and $53.29 \%$ after 15 and $30 \mathrm{mg} / \mathrm{kg} \mathrm{U}-74389 \mathrm{G}$ administration respectively $(\mathrm{P}<.001)$ in rats myocardial IR. Finally, U-74389G enhanced the survival rate at the end of the experiment (from 40 to $87 \%$ ). The drug may have potential cardioprotective use in acute myocardial infarction. Stanimirovic DB et al. ${ }^{26}$ retarded LDH release and membrane 'leakiness' from oxidant-treated cells by the steroid antioxidants U-74389G $(5-20 \mu \mathrm{M})$ in rat cerebromicrovascular endothelial cells. Despite the bibliographic efficacies of U-74389G in LDH levels recession, it is noticed that the distance between the LDH levels of animals treated by U-74389G is significant with that of normal levels and restoration of values has not been achieved at the present experiment. The weakness of values restoration may be due to either short U-74389G action study time or low U-74389G dosage. ${ }^{27}$

Table 6 The alteration influence of U-74389G in connection with reperfusion time

\begin{tabular}{lllll}
\hline p-values Increase & $95 \%$ c. in. & Reperfusion Time & t-test & glm \\
\hline$+958.4 \mathrm{IU} / \mathrm{L}$ & $266.9372 \mathrm{IU} / \mathrm{L}-1649.863 \mathrm{IU} / \mathrm{L}$ & $\mathrm{Ih}$ & 0.0369 & 0.0093 \\
$+797.65 \mathrm{IU} / \mathrm{L}$ & $352.61 \mathrm{I} 4 \mathrm{IU} / \mathrm{L}-1242.689 \mathrm{IU} / \mathrm{L}$ & $1.5 \mathrm{~h}$ & 0.0016 & 0.0008 \\
$+636.9 \mathrm{IU} / \mathrm{L}$ & $5.13447 \mathrm{I} \mathrm{IU/L}-1268.666 \mathrm{IU} / \mathrm{L}$ & $2 \mathrm{~h}$ & $0.010 \mathrm{I}$ & 0.0484 \\
$-148.05 \mathrm{IU} / \mathrm{L}$ & $-662.1633 \mathrm{IU} / \mathrm{L}-366.0633 \mathrm{IU} / \mathrm{L}$ & reperfusion time & 0.5383 & 0.5634 \\
$+378.9364 \mathrm{IU} / \mathrm{L}$ & $93.4767 \mathrm{IU} / \mathrm{L}-664.396 \mathrm{IU} / \mathrm{L}$ & interaction & - & 0.0106
\end{tabular}

Table 7 The predicted restore influence of U-74389G in connection with reperfusion time

\begin{tabular}{|c|c|c|c|c|}
\hline p-values Increase & $95 \%$ c. in & Reperfusion Time & t-test & gIm \\
\hline$+278.54|4| \mathrm{IU} / \mathrm{L}$ & - | $9.53909 \mid \mathrm{IU} / \mathrm{L}-576.6219 \mathrm{IU} / \mathrm{L}$ & Ih & 0.0674 & 0.0653 \\
\hline +376.7I585 IU/L & 198.732 IIU/L-554.6996 IU/L & $1.5 \mathrm{~h}$ & 0.0002 & 0.0001 \\
\hline +474.8903 IU/L & $256.5027 \mathrm{IU} / \mathrm{L}-693.2779 \mathrm{IU} / \mathrm{L}$ & $2 \mathrm{~h}$ & 0.0004 & 0.0002 \\
\hline$-75.34327 \mathrm{IU} / \mathrm{L}$ & $-290.6826 \mathrm{IU} / \mathrm{L}-139.996 \mathrm{I} \mathrm{IU} / \mathrm{L}$ & Reperfusion Time & 0.3375 & 0.4831 \\
\hline$+209.6325 \mathrm{IU} / \mathrm{L}$ & $98.5226 \mathrm{IIU} / \mathrm{L}-320.7424 \mathrm{IU} / \mathrm{L}$ & interaction & - & 0.0005 \\
\hline
\end{tabular}

Table 8 The (\%) predicted restore influence of U-74389G in connection with reperfusion time

\begin{tabular}{llll}
\hline Increase & \pm SD & Reperfusion Time & p-values \\
\hline $13.56 \%$ & $\pm 7.40 \%$ & Ih & 0.0663 \\
$18.78 \%$ & $\pm 4.52 \%$ & $1.5 \mathrm{~h}$ & $0.000 \mathrm{I}$ \\
$24.01 \%$ & $\pm 5.63 \%$ & $2 \mathrm{~h}$ & 0.0003 \\
$-3.75 \%$ & $\pm 5.46 \%$ & Reperfusion Time & 0.4103 \\
$10.43 \%$ & $\pm 2.82 \%$ & interaction & 0.0005 \\
\hline
\end{tabular}

\section{Conclusion}

U-74389G administration whether it interacted or not with reperfusion time kept significantly increased short - term the LDH levels. Perhaps, a longer study time or a higher drug dose may reveal the citing restore capacity.

\section{Acknowledgments}

This study was funded by Scholarship by the Experimental Research Center ELPEN Pharmaceuticals (E.R.C.E), Athens, Greece. The research facilities for this project were provided by the aforementioned institution. 


\section{Conflicts of interest}

The authors declare there is no conflict of interests.

\section{Funding}

None.

\section{References}

1. https://www.caymanchem.com/app/template/Product.vm/ catalog/75860.

2. Fenglin S, Jennifer C, Kenneth LA. 21-aminosteroid and 2(aminomethyl)chromans inhibition of arachidonic acid-induced lipid peroxidation and permeability enhancement in bovine brain microvessel endothelial cell monolayers. Free Radic Biol Med. 1995;19(3):349-357.

3. Tsompos C, Panoulis C, Toutouzas K, et al. The effect of the antioxidant drug "U-74389G" on $\gamma$-glutamyltransferase levels during ischemia reperfusion injury in rats. Literati Journal of Pharmaceutical Drug Delivery Technologies. 2016;2(2):8-12.

4. Tsompos C, Panoulis C, Toutouzas K, et al. The antioxidant drug" $\mathrm{U}-$ 74389G" attenuates the mean corpuscular hemoglobin concentration levels during hypoxia reoxygenation injury in rats. Journal of International Research in Medical and Pharmaceutical Sciences. 2016;9(4):158-163.

5. Tsompos C, Panoulis C, Toutouzas K, et al. The effect of the antioxidant drug “U-74389G” on. 2015.

6. Creatinine Levels during Ischemia Reperfusion Injury in Rats. Curr Urol. 9(2):73-78.

7. Tsompos C, Panoulis C, Toutouzas K, Triantafyllou A, Zografos G, et al. The effect of the antioxidant drug "U-74389G" on uric acid Levels during Ischemia reperfusion injury in rats. Ser J Exp Clin Res. 2016;17(2):1-1.

8. Pisarenko OI, Shulzhenko VS, Pelogerkina IuA, et al. Effects of exogenous apelin-12 on functional and metabolic recovery of isolated rat heart after ischemia. Kardiologiia. 2010;50(10):44-49.

9. Wang X, Zhang X, Ren XP, et al. MicroRNA-494 targeting both proapoptotic and antiapoptotic proteins protects against ischemia/ reperfusion-induced cardiac injury. Circulation. 2010;122(13):13081318 .

10. Yamagishi T, Bessho M, Yanagida S, et al. Severe, short-term food restriction improves cardiac function following ischemia/reperfusion in perfused rat hearts. Heart Vessels. 2010;25(5):417-425.

11. Xu C, Liu A, Sun H, et al. Beta2-Adrenoceptor confers cardioprotection against hypoxia in isolated ventricular myocytes and the effects depend on estrogenic environment. J Recept Signal Transduct Res. 2010;30(4):255-261.

12. Ciminelli M, Ascah A, Bourduas K, et al. Short term training attenuates opening of the mitochondrial permeability transition pore without affecting myocardial function following ischemia-reperfusion. Mol Cell Biochem. 2016;291(1-2):39-47.
13. Hoeven VJA, Molema G, Ter Horst GJ, et al. Relationship between duration of brain death and hemodynamic (in)stability on progressive dysfunction and increased immunologic activation of donor kidneys. Kidney Int. 2003;64(5):1874-1882.

14. Wang Y, Meyer JW, Ashraf M, et al. Mice with a null mutation in the $\mathrm{NHE} 1 \mathrm{Na}+-\mathrm{H}+$ exchanger are resistant to cardiac ischemia-reperfusion injury. Circ Res. 2003;93(8):776-782.

15. Wang WG, Deng ZS, Gong JL, et al. Protective effect of ischemic preconditioning on ischemia-reperfusion injury. Hunan Yi Ke Da Xue Хие Bao. 2000;25(4):351-353.

16. Baron A, Bilzer M, Gerbes AL. Short-term treatment with mycophenolic acid increases bile flow in continuously perfused and cold-preserved rat livers and does not affect hepatic ischemia-reperfusion injury. Transpl Int. 2002;15(6):265-271.

17. Ko KM, Mak DH, Poon MK, et al. Altered susceptibility to ischemiareperfusion injury in isolated-perfused hearts of short-term diabetic rats associated with changes in non-enzymatic antioxidants. Jpn $J$ Pharmacol. 2001;85(4):435-442.

18. Kume M, Yamamoto $\mathrm{Y}$, Saad S, et al. Ischemic preconditioning of the liver in rats:implications of heat shock protein induction to increase tolerance of ischemia-reperfusion injury. $\mathrm{J} \mathrm{Lab} \mathrm{Clin} \mathrm{Med.}$ 1996;128(3):251-258.

19. Jaeschke H, Smith CV, Mitchell JR. Reactive oxygen species during ischemia-reflow injury in isolated perfused rat liver. $J$ Clin Invest. 1988;81(4):1240-1246.

20. Shopova VL, Dancheva VY, Salovsky PT, et al. Protective effect of U-74389G on paraquat induced pneumotoxicity in rats. Environ Toxicol Pharmacol. 2007;24(2):167-173.

21. Vignes JR, Hugon J. In vitro efficacy of three lazaroids in a model of acute chemical neuronal hypoxia. Neurosci Lett. 2006;407(2):171-175.

22. Alhan E, Türkyilmaz S, Erçin C, et al. Effects of lazaroid U-74389G on acute necrotizing pancreatitis in rats. Eur Surg Res. 2006;38(2):70-75.

23. Di Monte DA, Tokar I, Langston JW. Impaired glutamate clearance as a consequence of energy failure caused by $\mathrm{MPP}(+)$ in astrocytic cultures. Toxicol Appl Pharmacol. 1999;158(3):296-302.

24. Fukuma K, Marubayashi S, Okada K, et al. Effect of lazaroid U-74389G and methylprednisolone on endotoxin-induced shock in mice. Surgery. 1999;125(4):421-430.

25. Ishizaki N, Zhu Y, Zhang S, et al. Comparison of various lazaroid compounds for protection against ischemic liver injury. Transplantation. 63(2):202-208.

26. Campo GM, Squadrito F, Altavilla D, et al. Protection of ischemic and reperfused rat myocardium by the nonglucocorticoid 21-aminosteroid U-74389G, a new inhibitor of lipid peroxidation. J Pharmacol Exp Ther. 1996;277(1):333-340.

27. Stanimirovic DB, Wong J, Ball R, et al. Free radical-induced endothelial membrane dysfunction at the site of blood-brain barrier:relationship between lipid peroxidation, $\mathrm{Na}, \mathrm{K}-\mathrm{ATPase}$ activity, and $51 \mathrm{Cr}$ release. Neurochem Res. 1995;20(12):1417-1427. 